\title{
Entrepreneurial networking: a blessing or a curse? Differential effects for low, medium and high performing franchisees
}

\author{
Maryse J. Brand • Evelien P. M. Croonen • \\ Roger T. A. J. Leenders
}

Accepted: 14 November 2016/Published online: 8 June 2017

C) The Author(s) 2017. This article is an open access publication

\begin{abstract}
Recent studies have called for a better understanding of the link between networking and entrepreneurial performance. We provide such understanding in three ways: by focusing on a specific entrepreneurial context (franchise systems), by developing a multifaceted theoretical framework and by highlighting a contingency that may affect the networkingperformance link. We combine knowledge and learning perspectives with a networking perspective to develop and test a multi-faceted framework on the effects of franchisee networking with peers within a franchise system ('peer networking') on franchisee unit performance. In particular, we argue that the performance benefits that franchisees draw from networking with their peers vary between low, medium and high performing franchisees. We use ordinary least squares (OLS) and Quantile Regression analyses to test our hypotheses with empirical data from a Dutch franchise system. Our results confirm that structural, resource and relational facets of franchisee peer networking affect
\end{abstract}

M. J. Brand • E. P. M. Croonen $(\bowtie)$

Faculty of Economics and Business, University of Groningen, PO Box 800, 9700 AV Groningen, The Netherlands

e-mail: e.p.m.croonen@rug.nl

M. J. Brand

e-mail: m.j.brand@rug.nl

R. T. A. J. Leenders

Department of Organization Studies, Tilburg University, PO Box 90153, 5000 LE Tilburg, The Netherlands

e-mail: r.t.a.j.leenders@tilburguniversity.edu unit performance, and that they benefit and harm low, medium, and high performing franchisees differently.

Keywords Entrepreneurship · Franchising · Local knowledge $\cdot$ Organizational learning $\cdot$ Peer network

JEL classification L25 Firm Performance; Size, Diversification, and Scope · L26 Entrepreneurship · D83 Search, Learning, Information and Knowledge, Communication, Belief, Unawareness · D85 Network Formation and Analysis: Theory · 21 Quantile Regression

\section{Introduction}

1.1 Networking and entrepreneurial performance

Many studies have found that networking improves entrepreneurial performance by providing entrepreneurs with access to a variety of important resources (e.g. Aldrich and Zimmer 1986; Hoang and Antoncic 2003; Slotte-Kock and Coviello 2009). However, other studies have pointed at the downsides of entrepreneurial networking - such as opportunity costs and governance problems - that may negatively affect firm performance (e.g. Watson 2007; Jack 2010; Rauch et al. 2016). Overall, there is still little consensus on how and under what conditions entrepreneurial networking affects firm performance (Stam et al. 2014). This paper contributes to this discussion by arguing and empirically demonstrating that networking can have differential effects for 
different types of entrepreneurs; more specifically, we find that for some entrepreneurs networking is a blessing, whereas for others it can be a curse.

Recent literature reviews and meta-analyses point at several critical issues in the networking-performance literature that may have caused the debate on the networking-performance link. First, the literature has suffered from conceptual vagueness regarding the types of resources shared, the types of networks in which they are shared and the types of entrepreneurial performance under study (Hoang and Antoncic 2003; Jack 2010). Second, researchers have largely focused on the effect of isolated network characteristics, such as an entrepreneur's network position or relationship quality, on entrepreneurial outcomes. This has resulted in a lack of consistent theoretical frameworks that take into account multiple facets of entrepreneurial networking in explaining performance (Jack 2010; Rauch et al. 2016). Third, only relatively few studies have taken into account contingencies, such as firm or industry characteristics, that might condition the effects of networking on entrepreneurial performance (Stam et al. 2014; Rauch et al. 2016).

Related to the abovementioned critical issues, our study contributes to the literature on the entrepreneurial networking-performance link in several ways. First, we decrease conceptual vagueness and provide more detailed knowledge of networking effects by focusing on franchise systems as a specific type of entrepreneurial context in which franchisees share a specific type of resource (i.e. ideas and knowledge on local marketing) with their fellow franchisees within the same franchise system (i.e. peers), resulting in a specific type of entrepreneurial performance (i.e. franchisee unit sales). Besides the fact that franchise systems are an important entrepreneurial context, such systems are very suitable for studying entrepreneurial phenomena since franchise systems provide a 'natural laboratory' where several conditions are standardized across franchiseeentrepreneurs (Szulanski and Jensen 2008).

Our second contribution is that we develop and test a multi-faceted framework of entrepreneurs' network characteristics and their effects on performance. We build on recent studies (Batjargal 2003; Stam et al. 2014) to distinguish three facets of an entrepreneur's network: structural, resource and relational characteristics. In recent years, several studies on the networkingperformance link in different organizational contexts have argued for combining structural network characteristics, such as an actor's network position, with other types of network variables, such as relational quality (Moran 2005), conduct (Afuah 2013) or partner attributes (Rodan and Galunic 2004). However, so far, these studies have not provided a consistent framework capturing the most relevant facets at once. Our study provides such a framework.

Our final contribution to the networking literature is that our study is among the few to include a contingency that may influence the effects of networking on entrepreneurial outcomes (following Stam et al. 2014; Rauch et al. 2016). Contingencies can be present at different levels, such as the individual entrepreneur (e.g. Ritter and Gemünden 2003), the firm (Stam et al. 2014), the type of industry (Rauch et al. 2016) or the economy (Stam et al. 2014). Some general networking studies have looked at actors' network utilization by studying the skills and abilities that influence how actors are able to utilize the resources acquired via their networks (e.g. Tsai 2001; Ritter and Gemünden 2003; Baker et al. 2016). However, entrepreneurship studies have rarely accounted for the heterogeneity among entrepreneurs in terms of how they utilize the resources deriving from their entrepreneurial networks (see Hayter (2015) for a brief discussion and Arenius and De Clercq (2005) and Seo et al. (2014) for exceptions). Our study contributes by including the entrepreneur's firm performance as an important contingency variable (cf. Seo et al. 2014). We propose that the level of performance reached by an entrepreneur affects the benefits the entrepreneur is able to draw from his networking activity.

\subsection{Franchisee networking and entrepreneurial performance}

We focus on an important and unique type of entrepreneurial context, namely business format franchise systems. As such, we also contribute to a considerable stream of literature aimed at describing and explaining franchising as an entrepreneurial phenomenon (Combs et al. 2011; Ketchen et al. 2011). Franchise systems are important since in many countries, they account for a major share of business; for example, they account for about 40,52 and $32 \%$ of retailing sales in respectively the USA, Australia and Germany (Dant et al. 2011). Franchise systems are unique because franchisees are semi-autonomous entrepreneurs who operate their businesses in a specific geographical location under a standardized business format with a uniform strategic 
positioning towards customers (Kaufmann and Eroglu 1998). Franchisees are part of a franchise system with the franchisor as the umbrella organization and with fellow franchisees (i.e. peers) and possibly franchisorowned units operating under the same business format in different locations (Gassenheimer et al. 1996).

Our study addresses an important knowledge gap in the franchising literature by studying how franchisees acquire their local knowledge and how this affects their unit performance. Knowledge is crucial in business format franchise systems (e.g. Darr et al. 1995; Gorovaia and Windsperger 2013), and many researchers have used knowledge and learning perspectives regarding franchising (e.g. Szulanski and Jensen 2008; Winter et al. 2012). These studies have focused on various research questions, such as what factors affect a franchisor's knowledge transfer mechanisms (Gorovaia and Windsperger 2013), whether systems or units within systems benefit more from the standardized knowledge of their franchisors or from the franchisees' local knowledge (e.g. Kalnins and Mayer 2004; Jensen and Szulanski 2007) or how specific types of units influence organizational learning and hence system performance (e.g. Darr et al. 1995; Sorenson and Sørensen 2001). These studies typically assume that franchisees have both the room and the inclination to use their local knowledge to adapt the franchisor's business format to their own circumstances to improve their unit performance (Kaufmann and Eroglu 1998; Sorenson and Sørensen 2001). To attain such an optimal local fit, franchisees will try to increase the quantity and quality of their local knowledge. Since the franchisor has knowledge on the system level and, consequently, less knowledge on the franchisee's local level, an important question is how franchisees use their personal contact networks to acquire their local knowledge and how this affects their unit performance. To our knowledge, this question has not yet been addressed in the franchising literature. Since franchisees have a huge impact on their franchise system's success (Michael and Combs 2008), the lack of understanding on franchisee local knowledge acquisition and its impact on unit performance forms an important research gap, which we narrow by means of our study.

In studying the performance effects of franchisee networking activities, we aim to avoid the aforementioned three critical issues in the networkingperformance literature. First, we prevent conceptual vagueness by focusing specifically on franchisees' acquisition of local marketing knowledge from their franchisee peers and the impact on franchisees' unit sales performance. Franchising literature so far has paid very little attention to knowledge sharing among franchisee peers. Only the studies of Darr et al. (1995), Darr and Kurtzberg (2000) and Turner and Pennington (2015) have explicitly focused on knowledge transfer among franchisees within franchise systems. Darr et al. (1995) found that operational knowledge is mostly shared between units owned by the same franchisee and less likely to be shared among units owned by different franchisees, whereas Darr and Kurtzberg (2000) found that strategic similarity of franchisees facilitates knowledge transfer among them. More recently, Turner and Pennington (2015) studied antecedents of franchisees' inclination to share knowledge. However, the effects of knowledge sharing on franchisee unit performance have remained unclear. Second, we avoid a focus on some isolated network characteristics by developing and testing a multi-faceted theoretical framework distinguishing a network's structural, resource and relational characteristics (Batjargal 2003; Stam et al. 2014). Finally, we take into account an important contingency variable by proposing that different franchisee types (i.e. low performers, medium and high performers) experience differential effects from their peer networking activities. This approach also fits with a more general tendency in the franchising literature of including the role of idiosyncratic franchisee characteristics in explaining unit-level outcomes (e.g. Kidwell et al. 2007; Cochet et al. 2008).

\section{Theoretical backgrounds and hypotheses}

\subsection{Defining franchisee local knowledge}

Franchisors and franchisees have very different types of knowledge (Kalnins and Mayer 2004; Szulanski and Jensen 2006). The franchisor mainly has generic knowledge at the system level: ideally, the franchisor knows which attributes of the business format are replicable and worth replicating, how these attributes are created and in which types of environments they are worth replicating (Winter and Szulanski 2001). Franchisors typically codify their knowledge and distribute standardized routines in the form of a defined business format to their franchisees (Szulanski and Jensen 2008; Winter et al. 2012; Gorovaia and Windsperger 
2013). As a result, the knowledge provided by the franchisor will not be perfect for any one location, but it should be generic enough to be valuable to franchisees at all locations. However, each franchisee needs knowledge about the local environment of its unit (e.g. customer preferences, competition, labour market developments) and the management of its unit (e.g. local HRM policies, local marketing activities) to run the local unit effectively. We define this type of knowledge as franchisee local knowledge. A franchisee's local knowledge is idiosyncratic, and it is mostly non-codified as opposed to codified (Kalnins and Mayer 2004; Knott 2003). Consequently, the franchisee's local knowledge is generally not possessed by the franchisor, and franchisees need other sources (their peers in this study) for acquiring their local knowledge.

'Franchisee local knowledge' is still a general classification, and different types of local knowledge can be relevant in a franchise setting. We focus on a franchisee's local marketing knowledge: knowledge about the local market needs, the competitive situation and the marketing instruments that can be used locally next to the marketing instruments as imposed by the franchisor. Such marketing instruments typically include the products and services offered, the unit interior and exterior, promotion activities and price levels. A franchise system's centralization level (cf. Windsperger 2004; Mumdžiev and Windsperger 2011) determines how much freedom franchisees have in adopting local marketing instruments, for example offering new products/ services or adopting their own promotion activities. It is not uncommon for franchisors to allow their franchisees to develop local tailor-made marketing activities, although usually these are developed in addition to the system-wide marketing activities executed by the franchisor (Windsperger 2004). In sum, our study focuses on the characteristics of franchisees' peer networks for acquiring local marketing knowledge, which we link to an objective marketing performance measure, namely unit sales levels.

\subsection{Theoretical framework}

In recent years, several studies (e.g. Tsai 2001; Hansen 2002; Baker et al. 2016) have combined a networking perspective with knowledge and learning perspectives to explain a range of outcomes of networking behaviour. The main idea behind such studies is that actors' learning from network partners requires access to valuable knowledge via those partners and, subsequently, actors need to be able to utilize this knowledge.

Having access to valuable knowledge relates to three different facets of an entrepreneur's network (Batjargal 2003, Stam et al. 2014): structural characteristics ('where you reach'), resource characteristics ('whom you reach') and relational characteristics ('how you reach'). First, the structural characteristics refer to the structure of an actor's overall network of relations and include for example the entrepreneur's network size or network position (Tsai 2001; Batjargal 2003; Reinholt et al. 2011). We focus on the entrepreneur's network position as this oft-studied type of characteristic captures the informational (dis)advantages that result from an entrepreneur's position in the knowledge sharing network. The more strategic the position of an actor within a network, the more (and the more timely) access the actor has to the knowledge and expertise of others in the network (Reinholt et al. 2011; Stam et al. 2014; Hayter 2015). This type of variable is important because it affects the quantity of knowledge to which an actor has easy access to.

Second, the network's resource characteristics refer to the resources that an actor has access to through the entrepreneur's network partners. These partner resources are important because they determine the potential value that an actor can derive from its partners (Adler and Kwon 2002; Zaheer and Bell 2005). Examples of such variables reflecting the value of network partners are 'resource richness' (Batjargal 2003), partners' skills, qualities or know-how (Kwon and Adler 2014) or partners' innovative capabilities (Zaheer and Bell 2005). In this study, we use the term partner quality to indicate the level of relevant marketing-related skills, qualities and know-how of the network partners which provides an actor with access to a high quality of knowledge.

The third and final group of networking variables are the relational characteristics, reflecting the nature of interactions between an actor and its network partners. These include, for example, the duration of relationships (Kim and Aldrich 2005) or the geographic distance (Kolympiris and Kalaitzandonakes 2013). Prior research has pointed at tie strength as an important relational network characteristic affecting the ease of knowledge transfer between partners (e.g. Uzzi 1997; Van Wijk et al. 2008). Strong ties consist of frequent interaction with peers nearby, while weak ties point at limited access to peers located far away. We use this 
concept of tie strength to capture the ease of knowledge transfer between an actor and its network partners.

The above three groups of network characteristics impact the quantity, the quality and the ease of transfer of knowledge that an actor has access to via its network partners. However, the access an actor has to valuable knowledge is only one side of the coin; the extent to which knowledge access translates into firm performance also depends on how well actors can actually utilize this knowledge. We refer to this as an actor's 'network utilization' (Baker et al. 2016). Recent work by Stam et al. (2014), Hayter (2015) and Rauch et al. (2016) provides examples of studies demonstrating that characteristics and capacities of actors affect if and to what extent they can benefit from the network resources they have access to. The meta-analysis of Rauch et al. (2016), however, clearly demonstrates that the majority of network studies still does not include such contingencies. Building on learning and knowledge perspectives, an actor's network utilization is contingent upon two characteristics. The first one is the actor's ability to recognize, assimilate and apply new knowledge. We refer to this as absorptive capacity (following many authors, such as Cohen and Levinthal 1990, Tsai 2001). The second one is the extent to which the acquired knowledge is useful given the entrepreneur's idiosyncratic circumstances (Seo et al. 2014; Baker et al. 2016). The literature points at two important aspects of such knowledge usefulness. First, new knowledge is particularly useful for an actor if it stems from a partner that has a high partner quality but that is also more knowledgeable than the actor itself (cf. Lane and Lubatkin 1998; Monteiro et al. 2008). This relative position of the actor vis-à-vis peers determines the potential added value to be gained from peers. High quality actors often have less to learn, particularly from lower quality partners with a small knowledge base. Second, the usefulness of knowledge for a specific actor depends on whether the knowledge offered fits with the actor's knowledge needs, which in turn depends on a firm's characteristics such as a firm's innovation orientation (Xu 2015) or firm performance (Seo et al. 2014). For example, $\mathrm{Xu}$ (2015) demonstrates that firms that aim for radical innovation need access to broad rather than deep knowledge, and Seo et al. (2014) find that low performing firms benefit more from access to basic knowledge on primary business functions rather than knowledge on secondary business functions, whereas for high performers it is the other way around.
Translating the above arguments to our theoretical framework for a franchise context, we posit that a franchisee's structural (i.e. network position), resource (i.e. partner quality) and relational (i.e. tie strength) network characteristics affect the quantity and quality of the knowledge to which the franchisee has access and the ease of knowledge transfer. Moreover, our framework points at network utilization as an important contingency variable influencing the actual utilization of the accessible knowledge by the franchisee. Following Seo et al. (2014), we posit that attained franchisee unit performance is an adequate indicator of such network utilization for three reasons. First, linked to the absorptive capacity argument, high-performance franchisees are likely to have a higher absorptive capacity than low-performance franchisees; high performers already have the experience and knowledge needed to identify and successfully implement new knowledge in their units. Second, linked to the relative position argument, we propose that high-performance franchisees may benefit differently from their peers compared to low performing franchisees since the relative knowledge position of high performers is strong. Finally, related to the knowledge needs argument, we posit that low performing franchisees require basic knowledge on how to attain higher sales levels, whereas the high performing franchisees already understand their business and need broader and more complex knowledge to take their business to the next level (cf. Seo et al. 2014; Xu 2015).

Figure 1 depicts an overview of the theoretical framework. In Section 2.3, we present our study's hypotheses.

\subsection{Hypotheses}

\subsubsection{Structural network characteristics: network position}

Structural network characteristics capture 'where you reach': does an actor only have access to knowledge of direct network partners or does the actor's knowledge scope reach further? An actor's position in a specific network can impose constraints or offer opportunities (Tsai 2001; Zaheer and Bell 2005; Reinholt et al. 2011). An important concept reflecting the advantageousness of an actor's network position is betweenness centrality (Freeman 1977, 1979; Wasserman and Faust 1994; Fang et al. 2016; Lai 2016). The higher the betweenness centrality of an actor, the more access it has to other 
Fig. 1 Theoretical framework. The theoretical framework is to be read as follows: unit performance is affected (solid lines) by three types of networking characteristics, whose effects are expected to vary with unit performance itself (dashed lines)

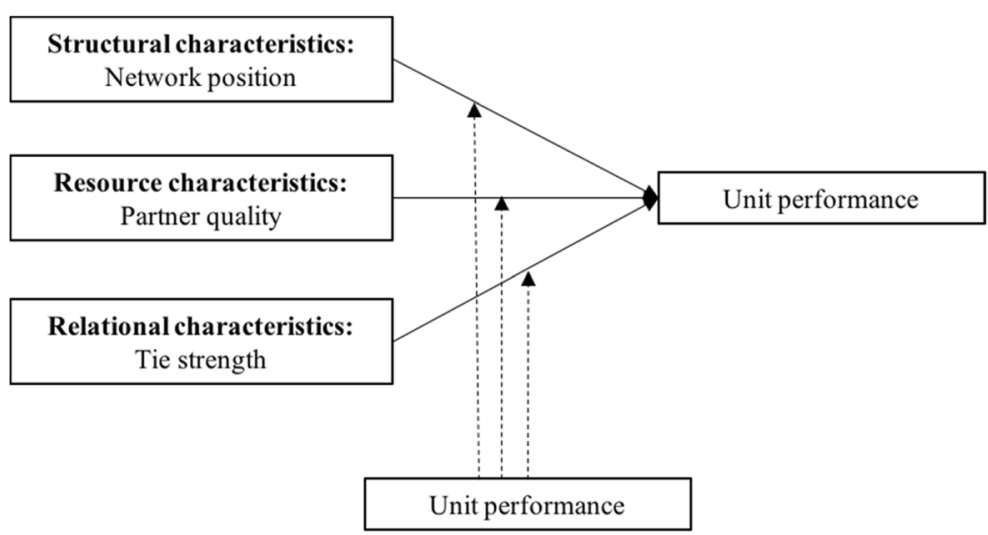

actors and the more influence it has as an intermediary between other actors (Hanneman and Riddle 2005; Reinholt et al. 2011). The main argument is that central actors can act as an information gateway that disseminates and receives relevant information and knowledge throughout the network; as a result, the more central the actor, the greater its access to knowledge and other actors' best practices, which may positively affect this actor's performance (Soh 2010; Reinholt et al. 2011; Fang et al. 2016).

In this study, a franchisee's position in its peer network presents the franchisee with constraints or opportunities to access marketing knowledge. The peer network has clear boundaries and consists of all franchisees of the same franchise system, and each franchisee has a specific position in this peer network. A franchisee's betweenness centrality reflects this franchisee's opportunities to access information and knowledge from its peers, both directly (through the direct ties that the franchisee maintains) and indirectly (through the ties maintained by the franchisee's direct partners and further ties in the network that are connected to those). This leads to the following hypothesis:

- H1a: Centrality in the peer network is positively associated with unit performance.

While an actor's network centrality affects the quantity of knowledge to which an actor has access, whether an actor benefits from its network or not depends on its network utilization (Baker et al. 2016). The low absorptive capacity of low performing franchisees is expected to affect this network utilization; unsuccessful franchisees will be less able to benefit from the quantity of knowledge inherent to a central network position as their lower absorptive capacity prevents them from recognizing, assimilating and applying knowledge in their own units. This leads to the following hypothesis:

- H1b: The positive association of centrality with unit performance is stronger for high performers than for medium and for low performers.

\subsubsection{Resource network characteristics: partner quality}

Resource network characteristics capture 'whom you reach': does an actor have access to partners with performance-enhancing knowledge and expertise or does an actor mainly connect to partners who have little beneficial knowledge and insights to share? Firms vary in their managerial priorities (or 'strategic orientations') that guide their attitudes, practices and knowledge development, which in turn affect their performance (Darr and Kurtzberg 2000; Noble et al. 2002). Considering these managerial priorities, we build on Darr and Kurtzberg (2000) by posing that network partners will develop two basic types of performance-enhancing knowledge: external 'sales' knowledge aimed at attracting revenue streams from customers and internal 'operational' knowledge, relating to effectively securing and allocating the firm's resources. Together, these reflect both the external and internal capabilities of firms.

Peer sales quality Research has found the knowledge and expertise of an actor's partners to contribute to the actor's performance (Adler and Kwon 2002; Batjargal 2003; Chiu et al. 2006). For example, entrepreneurs seeking to improve innovative performance are likely 
to benefit from networking with partners with strong innovative capabilities (Zaheer and Bell 2005). Similarly, firms seeking to achieve a growth in revenue streams benefit from networking with partners who already achieved such high revenue streams (Stuart 2000), and firms seeking to improve their sales performance need network partners with marketing knowledge (Tran et al. 2010). In sum, the network partners' quality has an important influence on an actor's performance. We hypothesize that firms that are networking with peers that have shown to be able to generate high sales levels will experience a positive effect on their own sales performance. Firms with high sales levels ('sales quality') demonstrate that they are able to successfully attract customers and are likely to have relevant marketing knowledge and expertise (cf. Arnett and Wittmann 2014). Their potential knowledge contributions make them attractive network partners (Darr and Kurtzberg 2000; Chiu et al. 2006). This argumentation leads to the following hypothesis:

- H2a: Peer sales quality is positively associated with unit performance.

Having high quality network partners influences the 'absolute' quality of the knowledge a franchisee has access to. However, as pointed out in Section 2.2, the knowledge has to be useful given the franchisee's specific circumstances. First, following the relative position argument (Lane and Lubatkin 1998; Monteiro et al. 2008), high performing franchisees already possess high quality knowledge themselves and are thus in a high relative position compared to their peers and will benefit less from these peers. In contrast, unsuccessful franchisees can benefit a lot from networking with high sales quality peers because they have much to improve. Second, building on the knowledge needs argument, low performing franchisees benefit more from the high quality sales peers since these can provide them with relevant basic knowledge on how to increase sales, whereas high performers already have such knowledge and need more complex knowledge to further improve their sales performance (cf. Chiu et al. 2006). This leads to the following hypothesis:

- H2b: The positive association of peer sales quality with unit performance is stronger for low performers than for medium and for high performers.
Peer operational quality Whereas 'peer sales quality' focuses on the extent to which a franchisee's peers are successful in attracting sales, another type of knowledge that will be beneficial to franchisees is knowledge about successful operational performance (Darr and Kurtzberg 2000; Noble et al. 2006). The ability to attract sales largely captures a firm's ability to successfully interact with its external environment and generate financial streams from the environment into the firm (Seo et al. 2014). Alternatively, operational performance refers to a firm's ability to manage its outgoing financial streams in relation to what is flowing in and requires aptitude in managing its internal operations. 'Peer sales quality' requires a successful external activity, whereas 'peer operational quality' requires successful external activity in combination with successful internal activity. High operational quality peers thus have a more diverse and complex knowledge base than peers with low operational quality; high operational quality peers have a sound causal understanding of the complex relationships between internal and external activities, leading to the profitability of their units (cf. Rodan and Galunic 2004). Given the large knowledge base of these high operational quality peers, we hypothesize that franchisees will benefit from networking with them. This leads to the following hypothesis:

- H3a: Peer operational quality is positively associated with unit performance.

However, we expect low performing and high performing franchisees to differ in their knowledge needs and thus in the extent to which they can benefit from these peers' diverse and complex knowledge bases. High performing franchisees have demonstrated that they are able to exploit their business effectively in their local environment and that they already have the basic knowledge required to attain high sales levels (cf. Seo et al. 2014). Further sales growth will ask for creative strategies to further explore the local opportunities, and for this, the franchisee will need diverse and complex knowledge that triggers its creativity (cf. Tran et al. 2010). In contrast, low performing franchisees first have to focus on attracting more sales by improving their basic knowledge (Seo et al. 2014), and they will thus have less use for diverse and complex knowledge (Tran et al. 2010). Moreover, the high absorptive capacity of the high performers will also enable them to assimilate and apply the complex knowledge. Low 
performers will struggle more using this diverse and complex knowledge because of their lower absorptive capacity. This leads to the following hypothesis:

- H3b: The positive association of peer operational quality with unit performance is stronger for high performers than for medium and for low performers.

\subsubsection{Relational network characteristics: tie strength}

Relational network characteristics capture 'how you reach'; does an actor have relationships that are close by and easy to reach? How often does he/she interact with these partners? Tie strength is a widely used concept comprising these two different aspects of distance and frequency. Strong ties comprise close and frequent relations, whereas weak ties are distant and infrequent (Afuah 2013; Stam et al. 2014). As we will explain below, distance and frequency have distinct effects on the beneficial outcomes of the ties.

Peer distance The concept of distance can have different meanings in organizational contexts, such as cognitive, social or geographical distance (Dolfsma and Van der Eijk 2015). We focus on geographical distance between franchisees and their peers since geographical distance between units is a defining characteristic of franchise systems (Darr et al. 1995; Darr and Kurtzberg 2000).

Previous research has described both the advantages and disadvantages of geographical distance. ${ }^{1}$ Networking with distant peers may result in the acquisition of new and diverse knowledge that is not available in the franchisee's immediate environment (Darr and Kurtzberg 2000; Dolfsma and Van der Eijk 2015); on the other hand, geographical distance decreases the ease of interaction and knowledge interpretation (i.e. knowledge transfer) and increases the costs of knowledge transfer (Cramton 2001; Kolympiris and Kalaitzandonakes 2013). Effective acquisition of local marketing knowledge from peers requires a careful understanding of these peers' contextual circumstances and distance may really hamper this understanding (Cramton 2001). We therefore

\footnotetext{
${ }^{1}$ Some sources focus on partner geographical proximity (e.g. Kolympiris and Kalaitzandonakes 2013; Darr and Kurtzberg 2000), which we consider the antonym of geographical distance in our argumentation.
}

hypothesize that the multiple disadvantages of peer distance outweigh the advantage, which leads to:

- H4a: Peer distance is negatively associated with unit performance.

Generally speaking, distant ties have a relatively high newness of knowledge, low ease of knowledge transfer and high costs. Considering the differences between high and low performing franchisees as regards absorptive capacity and knowledge needs, we hypothesize that the effects of peer distance also differ between these groups. The difficulties with the interpretation of local marketing knowledge from geographically distant peers will be larger for low performing franchisees than for high performing franchisees. Also, the usefulness of this new knowledge will be less for low performing franchisees as they may benefit more from basic knowledge than from diverse knowledge. Hence:

- H4b: The negative association between peer distance and unit performance is stronger for low performers than for medium and for high performers.

Peer communication frequency Close relationships can only develop when actors are able to meet each other and exchange ideas frequently. Having a high frequency of communication with one's network partners has the advantage of an easy knowledge flow, but it has the disadvantage of providing reducing marginal gains by spawning less new knowledge at each subsequent interaction and perhaps even creating redundancy of knowledge (Stam et al. 2014; Rauch et al. 2016). Entrepreneurs face resource and time constraints (Cooper et al. 1997; Christen et al. 2009), which means they cannot spend excessive amounts of time on networking (Watson 2007). The more frequent a franchisee's peer network contacts, the higher the costs. Although communication frequency has positive effects on knowledge flow, we propose that these benefits are outweighed by the reduction of the value of the acquired knowledge and the high resource costs associated with highfrequency networking, both in managerial time and money (Watson 2007). We therefore propose the following hypothesis:

- H5a: Peer communication frequency is negatively associated with unit performance. 
Building on the knowledge needs argument, we propose that high performing franchisees already have a well-developed local marketing knowledge base, which increases the chances of them receiving redundant, nonactionable, knowledge. As a result, they may suffer even more from frequent network contacts than low performing franchisees (cf. Watson 2007). Hence, costly frequent interactions with contacts that provide redundant information are particularly detrimental to high performers, leading to:

- H5b: The negative association between peer communication frequency and unit performance is stronger for high performers than for medium and for low performers.

\section{Methodology}

\subsection{Empirical setting and data collection}

\subsubsection{Empirical setting and sample}

We collected empirical data within one franchise system to control for country, industry and franchise system differences. Even though the choice for one franchise system may limit the external validity of our study, it substantially improves internal validity (Davies et al. 2011). Given that this project is among the first to study the impact of franchisee (peer) networking on unit performance, it is important to first establish internal validity since internal validity is an important prerequisite for external validity (Gibbert et al. 2008). Specific characteristics of the country, industry and the franchise system may influence the importance of having local market knowledge for franchisees and the availability of such knowledge. Between countries and industries, there may for example be institutional or cultural differences. At the level of franchise systems, there may for example be differences in the geographical dispersion of units (Szulanski and Jensen 2008), in centralization levels (Windsperger 2004; Mumdžiev and Windsperger 2011) or in the use of instruments for knowledge sharing (Dada et al. 2012).

ENJOY (pseudonym) is a Dutch franchise system that started in the mid-1990s in a specific sub-sector of the fast food industry. At the time of data collection (winter of 2009/2010), many industries were seriously hurt by the crisis; the fast food industry in the Netherlands, however, was relatively stable with .1 to $1.4 \%$ annual growth (Rabobank 2014). At the time of data collection, the ENJOY system had 105 franchised units that were owned by 78 franchisees. However, out of these 105 units, 14 units were different as these were sitdown restaurants at central train stations and very large city centres rather than delivery services in suburban areas. To control for these unit differences, we decided to focus on the remaining 91 units. These units were owned by 69 franchisees, of whom 44 participated in our study. However, due to missing data (especially for the financial performance data), we used the responses of 33 franchisees, resulting in a net response rate of $48 \%$. Regarding the non-respondents, there is no reason to assume that they will have very different networking characteristics. In order to quantitatively assess non-response bias, we have performed several tests by comparing respondents and non-respondents on different dimensions. The Welch $t$ test demonstrates that the means of total sales between the respondents and non-respondents are the same $(t=.47, p=.64)$. The $F$ test shows that the variances of the sales between the two groups are the same $(F=.77$, $p=.43)$. The Kolmogorov-Smirnov test indicates that the sales volumes of the two groups come from the same distribution $(D=.15, p=.64)$. The tests thus indicate that non-response bias is unlikely.

The ENJOY system has a high level of centralization on several decision areas (cf. Windsperger 2004), such as assortment, procurement, unit presentation, national promotion activities, accounting systems, employee training and investments. However, the ENJOY franchisees still have room to make their own local decisions regarding pricing, local promotion and employee recruitment. Franchisees' pricing and local promotion decisions are typically related to their local marketing knowledge, which is why we have specifically asked the franchisees about the networks partners that provide them with knowledge to make decisions regarding local promotion and pricing in their own units. By focusing on these specific local marketing decisions in our interviews with the franchisees, we were able to make a vague concept as 'local marketing knowledge' easier for them to understand. 


\subsubsection{Procedures regarding data collection}

This paper was part of a larger project to explain franchisee networking characteristics and to understand their consequences. We collected detailed quantitative and qualitative data for each franchisee respondent. Since the complexity of the topic was high and part of the information might have been regarded as sensitive, we collected the data by means of personal face-to-face interviews (Emans 2004). An additional advantage of interviews is that they provide the opportunity to gather additional qualitative contextual data that may help in interpreting the findings from the quantitative analysis. Each interview took between 60 and $90 \mathrm{~min}$ and took place at the franchisee's unit.

Each interview started with questions on the franchisee's demographics (e.g. number of units owned, years of experience as an ENJOY franchisee). Obviously, the largest part of the interview focused on understanding a franchisee's structural, resource and relational network characteristics. We first asked the franchisees a question about which network partners (i.e. specific individuals) they consider most important regarding obtaining ideas for their own local promotion and pricing. These individuals could belong to the category franchisee peers, the franchisor, professionals and non-professionals. We then asked different questions on each partner and the relationship with these partners, such as the type of partner, the frequency of contact and a qualitative explanation for the reason why the partner is so important to the respondent. These questions enabled us to measure the franchisee's direct network. We later repeated this procedure, asking each franchisee to indicate up to three most important franchisees from the peer network only. On occasion, this yielded additional peers, but many of them were already reported by the respondent in the former network question. Obviously, in the analyses, we ultimately took into account any overlap in a franchisee's peer and direct network. The advantage of this approach is threefold: it provided the respondents with the opportunity to mention all promotion-relevant contacts, it urged them to zoom in on their peers and it allowed us with the opportunity to check the reliability of their answers. Checking reliability was possible because we asked respondents about details for every contact mentioned, and details of contacts that were mentioned twice were asked for twice as well; we found very little deviation between the first mention and the second mention of the same peer, indicating high reliability of the measurements.

\subsection{Issues of measurement}

Table 1 summarizes the measurement properties of the variables in this study.

\subsubsection{Dependent variable: unit performance}

The ENJOY franchisor allowed us to use objective sales data per unit from its benchmarking system. The use of

Table 1 Measurement properties

\begin{tabular}{|c|c|c|}
\hline Variables & Measure & Data source \\
\hline \multicolumn{3}{|l|}{ Dependent variable } \\
\hline $\begin{array}{l}\text { Unit } \\
\text { performance }\end{array}$ & $\begin{array}{l}\text { Total level of unit sales over } \\
\text { a period of } 43 \text { weeks } \\
\text { (from January } 2009 \text { to } \\
\text { October 2009) divided by } \\
\text { 1000. In case a franchisee } \\
\text { has two stores, this } \\
\text { number refers to the unit } \\
\text { in which the franchisee } \\
\text { itself is present most often }\end{array}$ & $\begin{array}{l}\text { Franchisor's } \\
\text { benchmark- } \\
\text { ing system }\end{array}$ \\
\hline \multicolumn{3}{|c|}{ Explanatory variables } \\
\hline $\begin{array}{l}\text { Centrality } \\
\text { (betweenness) }\end{array}$ & $\begin{array}{l}\text { The shortest paths between } \\
\text { all franchisees that a } \\
\text { franchisee is part of in the } \\
\text { peer network }\end{array}$ & $\begin{array}{l}\text { Franchisee } \\
\text { interviews }\end{array}$ \\
\hline $\begin{array}{l}\text { Peer sales } \\
\text { quality }\end{array}$ & $\begin{array}{l}\text { The average unit sales (in } \\
€ 1000 \text { ) of the franchisee's } \\
\text { peer ties }\end{array}$ & $\begin{array}{l}\text { Franchisor's } \\
\text { benchmark- } \\
\text { ing system }\end{array}$ \\
\hline $\begin{array}{l}\text { Peer operational } \\
\text { quality }\end{array}$ & $\begin{array}{l}\text { The average unit profits (in } \\
€ 1000 \text { ) of the franchisee's } \\
\text { peer ties }\end{array}$ & $\begin{array}{l}\text { Franchisor's } \\
\text { benchmark- } \\
\text { ing system }\end{array}$ \\
\hline Peer distance & $\begin{array}{l}\text { The average distance in } \\
\text { minutes travelling } \\
\text { between the franchisee } \\
\text { and its peer ties }\end{array}$ & $\begin{array}{l}\text { Franchisee } \\
\text { interviews }\end{array}$ \\
\hline $\begin{array}{l}\text { Peer } \\
\text { communication } \\
\text { frequency }\end{array}$ & $\begin{array}{l}\text { The average number of } \\
\text { monthly contacts } \\
\text { between the franchisee } \\
\text { and its peer ties }\end{array}$ & $\begin{array}{l}\text { Franchisee } \\
\text { interviews }\end{array}$ \\
\hline \multicolumn{3}{|l|}{ Control variables } \\
\hline $\begin{array}{l}\text { Franchisee } \\
\text { experience }\end{array}$ & $\begin{array}{l}\text { The franchisee's experience } \\
\text { as an ENJOY franchisee } \\
\text { in number of years }\end{array}$ & $\begin{array}{l}\text { Franchisee } \\
\text { interviews }\end{array}$ \\
\hline $\begin{array}{l}\text { Franchisee work } \\
\text { floor hours }\end{array}$ & $\begin{array}{l}\text { The franchisee's number of } \\
\text { hours per week invested } \\
\text { in the franchise }\end{array}$ & $\begin{array}{l}\text { Franchisee } \\
\text { interviews }\end{array}$ \\
\hline
\end{tabular}


sales data has several advantages. First, from a theoretical viewpoint, it is highly likely that sales are directly affected by franchisees' local marketing activities that result from the franchisee's local marketing knowledge. Second, since the franchisor collected the financial performance data via its benchmarking system, we have no issues of common method bias in our data, and the data provide a good insight into the relative performance of each unit viz. the other units. Finally, since fees for the franchisor are often (largely) based on unit sales, unit sales are also a relevant measure from a franchisor's practical perspective. We measured the performance of each franchisee as the unit's total level of sales over a 43-week period (in January 2009-October 2009). To decrease complexity, we divided total sales by 1000 .

\subsubsection{Explanatory variables: franchisee network characteristics}

We measured the franchisee's peer network ties by asking them to name their direct contacts with peers that are important and useful to them for gathering ideas and information related to local promotion and pricing. They could name as many network partners as they wanted; the median number of ties to other franchisees was three. By the way the data were collected, network ties were directed; one franchisee could be in contact with another franchisee in order to get advice on pricing, but that does not necessarily imply that pricing advice was also returned. Still, advice was often offered to each other by both parties (reciprocity was .3).

Betweenness centrality In the literature, there are many different specific operationalizations of network centrality (Lai 2016). We focus on betweenness centrality: the extent that a franchisee is located on shortest paths between other franchisees. We measured a franchisee's betweenness by the number of shortest paths between all franchisees in the network that this specific franchisee is part of, following Brandes (2001). This measure reflects the extent to which a franchisee is centrally located between its peers and is likely to be on informationsharing paths. The higher a franchisee's betweenness, the more the franchisee is 'in the loop' and the more it is expected to see what is going on in the interaction between other franchisees. ${ }^{2}$

Peer sales quality This variable measures the average sales (in $€ 1000$ ) of the peer network partners of the franchisee. We received this information from the franchisor's benchmarking system.

Peer operational quality This variable measures the average financial bottom line result or unit profits (in $€ 1000)$ of the peer contacts of the franchisee. We received this information from the franchisor's benchmarking system.

Peer distance This variable measures the average travel distance (in minutes) between the franchisee and its peer contacts.

Peer communication frequency This is measured by the number of times per month the franchisee engages in pricing, advertising and marketing-related interaction with its peer contacts.

\subsubsection{Control variables}

In general, the performance of a franchised unit depends on three types of determinants: general environmental characteristics, local unit characteristics and franchisee characteristics (Fenwick and Strombom 1998). General environmental characteristics comprise for example the industry structure and franchise system characteristics, and our study controls for such characteristics by focusing on one single franchise system in a specific industry in one country. The local unit characteristics refer to the market potential of the units, which is related to the type of location (urban or rural, Croonen et al. 2016, or the level of competition, Kidwell et al. 2007). As pointed

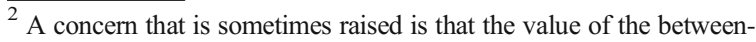
ness of one actor in a network might be negatively correlated with the betweenness of others and measurements would therefore not be fully independent. This concern is not of importance in our study. First, mathematically, the high betweenness of one actor does not necessarily imply that another actor must have lower betweenness. In fact, the correlation between the betweenness scores of franchisees across all dyads is -0.02 , which is negligible. Second, any non-independence of betweenness scores is only problematic if it invalidates the assumption of independence of disturbances in an OLS model. In our OLS model, this was tested with the Durbin-Watson test, which showed that the assumption of error independence cannot be rejected $(p<.23)$. Further, our main model is the quantile regression model, which does not make distributional assumptions for the error terms.
} 
out in Section 3.1.1, this study's design also largely controls for these local unit characteristics since all units operate under the same business format in suburban locations in which delivery comprises the largest part of the sales. Finally, franchisees' personal and behavioural characteristics are important, since these help in explaining differences in unit outcomes even within a single franchise system with very similar units (Dant and Gundlach 1999; Fenwick and Strombom 1998). This category comprises for example the networking variables included in our model. As an additional control variable, we include the franchisee's experience in the focal franchise system as this affects the skills of the franchisee (Dant and Gundlach 1999). The more experienced the franchisee is in the franchise system, the more the store's performance might benefit because the franchisee has become knowledgeable about what makes the business format work. We also control for the number of hours per week the franchisee spends on the work floor of his/her unit. An entrepreneur's time is scarce, and the way entrepreneurs allocate this limited time among different activities and the attention they pay to these activities will influence firm performance (Cooper et al. 1997; Christen et al. 2009). The higher the number of hours the franchisee spends on the work floor, the less time and attention the franchisee has to network and to reflect on his marketing activities, and the more the focus of the franchisee is likely to shift to internal day-to-day issues rather than to external salesrelated issues.

\subsection{Estimation methods}

In our analyses, we combine traditional ordinary least squares (OLS) with Quantile Regression (QR) and compare the results for both analyses. This also enables us to assess the value of applying each method, as is often done in other QR studies (e.g. Goedhuys and Sleuwaegen 2010; Ramdani and Van Witteloostuijn 2010). We provide a brief primer to $Q R$ in the Appendix.

Traditional regression methods, such as OLS or logistic regression, are focused on the mean: they summarize the relationship between an outcome and a set of explanatory variables by describing the mean outcome for each fixed value of the explanatory variables - OLS therefore is also known as conditional mean modelling. A drawback of such a model is that it does not describe non-central locations, such as the effect that the explanatory variables may have specifically on observations in the lower tail or upper tail of the distribution. Koenker and Bassett (1978) introduced a natural extension of the linear regression model called quantile regression, which models conditional quantiles as functions of a set of explanatory variables. Whereas the traditional linear regression model only specifies the change in the conditional mean of the dependent variable associated with a change in the explanatory variables, the QR model specifies the changes in the conditional quantile. The researcher can choose which quantiles (or 'percentiles') are of relevance to the research at hand-when the .5 quantile is chosen the model is better known as median regression.

Since our hypotheses make a distinction between three groups of franchisees (those in the lower tail of the performance distribution, those in the middle and those in the upper tail), we focus on three percentiles: .25 (representing the effect of the explanatory variables on a franchisee that only does better than $25 \%$ of the franchisees in the sample), .50 (representing the effect on a franchisee with median performance) and .75 (representing the effect on a franchisee that achieves a performance level that is better than that of $75 \%$ of the sample). In this way, we estimate regression coefficients that pertain to franchisees at each of these performance levels and compare coefficients and statistical significance between them. QR has several statistical advantages over regular regression: it is robust to outliers as well as to distributional assumptions. Whereas OLS often relies on larger sample sizes in order to remedy potentially violated distributional assumptions, QR does not require larger sample sizes for this purpose. QR can deal naturally with highly skewed data such as income or sales, without the need to transform such data into mode well-behaved data shapes (Koenker 2005; Hao and Naiman 2007).

\section{Results and discussion}

\subsection{Introduction to the results}

The key descriptives and statistics for all variables appear in Tables 2 and 3. Table 3 shows that performance correlates positively with occupying a central position in the peer network, with networking with peers with high sales quality and with having more experience as a franchisee in the franchise system. There is a moderate 
Table 2 Descriptives

\begin{tabular}{|c|c|c|c|}
\hline Variables & Mean & $\begin{array}{l}\text { Standard } \\
\text { deviation }\end{array}$ & Min.--max. \\
\hline \multicolumn{4}{|l|}{ Dependent variables } \\
\hline $\begin{array}{l}\text { Unit performance (sales, in } \\
€ 1000 \text { ) }\end{array}$ & 243.4 & 109.2 & $\begin{array}{l}23.4- \\
455.6\end{array}$ \\
\hline \multicolumn{4}{|l|}{ Explanatory variables } \\
\hline Centrality (betweenness) & 18.7 & 33.7 & $.0-143.7$ \\
\hline Peer sales quality (in €1000) & 311.0 & 84.4 & $\begin{array}{r}106.1- \\
455.6\end{array}$ \\
\hline $\begin{array}{l}\text { Peer operational quality (in } \\
€ 1000 \text { ) }\end{array}$ & 234.9 & 229.2 & $\begin{array}{c}-465.4 \text { to } \\
502.3\end{array}$ \\
\hline Peer distance (minutes) & 39.8 & 15.8 & $15-80$ \\
\hline $\begin{array}{l}\text { Peer communication } \\
\text { frequency (times per month) }\end{array}$ & 5.4 & 6.9 & $.3-30.0$ \\
\hline \multicolumn{4}{|l|}{ Control variables } \\
\hline Franchisee experience (years) & 4.6 & 3.5 & $1-13$ \\
\hline $\begin{array}{l}\text { Franchisee work floor hours } \\
\text { (hours per week) }\end{array}$ & 39.8 & 18.8 & $8-90$ \\
\hline
\end{tabular}

positive significant correlation between the average sales quality of a franchisee's peers and the peers' average operational quality. This makes sense, because higher sales are likely to contribute positively to operational results. Unexperienced franchisees also put in more work floor hours. Separate analyses (not shown) indicate that there are no multicollinearity issues in any of our analyses.

We present the results of the OLS and QR models in Table 4. QR estimates the regression coefficients of the explanatory variables for franchisees at particular quantiles in the overall performance distribution: .25 (i.e. low performers), .50 (i.e. medium performers) and
.75 (i.e. high performers). In the distribution of sales in our sample, the 25 th quantile equals a total sales volume (over the 43 weeks of measurement) of about $€ 159 \mathrm{~K}$, the median sales level is about $€ 228 \mathrm{~K}$ and the high performing franchisees at the .75th quantile of the distribution have a sales level of about $€ 321 \mathrm{~K}$. In OLS analyses, it is common to transform sales volume before running the analysis (usually, by taking the logarithm), but this is unnecessary in QR analyses (see the Appendix).

Since we hypothesize that networking characteristics may have differential effects on a franchisee depending on the position of the franchisee in the performance distribution, we expect differences in parameter estimates and statistical significance between firms along the three considered quantiles. In Table 4, we present both the results of the OLS regression and the three quantile regressions. In the OLS model, we leave the sales variable untransformed. This maximizes comparability between OLS and the QR results; besides this, the Shapiro-Wilk statistic of sales is not significant $(p<.72)$, which suggests that sales is quite normally distributed.

The type of hypothesis that follows from our quantile-based arguments (i.e. the 'b'-versions of the hypotheses) consists of several components; in a strict sense, the hypothesis would be rejected as soon as only one of the components does not hold. As a result, it is reasonable and more informative to discuss the extent to which each hypothesis is supported, rather than only drawing conclusions about the consolidated hypothesis per se. Besides a discussion of the empirical findings based on Table 4, we summarize the empirical findings graphically in Fig. 2, allowing for the visual comparison of the various effects.

Table 3 Correlation matrix

\begin{tabular}{|c|c|c|c|c|c|c|c|}
\hline & 1. & 2. & 3. & 4. & 5. & 6. & 7. \\
\hline 1. Unit performance & - & & & & & & \\
\hline 2. Centrality (betweenness) & $.54 * * *$ & - & & & & & \\
\hline 3. Peer sales quality & $.30 *$ & .13 & & & & & \\
\hline 4. Peer operational quality & .21 & .02 & $.55 * * * *$ & & & & \\
\hline 5. Peer distance & .10 & .17 & .13 & -.01 & & & \\
\hline 6. Peer communication frequency & .03 & $.31 *$ & -.23 & -.20 & -.18 & & \\
\hline 7. Franchisee experience & $.54 * * *$ & .03 & .19 & .12 & .17 & .12 & \\
\hline 8. Franchisee work floor hours & $-.58 * * * *$ & $-.37 * *$ & -.24 & -.14 & .01 & -.09 & $-.43 * * *$ \\
\hline
\end{tabular}

$* p<.10, * * p<.05, * * * p<.01, * * * * p<.001$, levels of significance 
Table 4 Results of OLS and QR with unit performance as the dependent variable

\begin{tabular}{lllll}
\hline Variables & OLS & QR25 & QR50 & QR75 \\
\hline Intercept & $210.40^{*}(76.49)$ & $73.31(138.64)$ & $169.72(120.68)$ & $328.39 * * * *(49.79)$ \\
Centrality (betweenness) & $1.76^{* * * *}(.46)$ & $1.51(1.29)$ & $1.75 * * *(.38)$ & $2.18 * * *(.37)$ \\
Peer sales quality & $.06(.19)$ & $.60 *(.34)$ & $.24(.31)$ & $-.29 * * *(.09)$ \\
Peer operational quality & $.02(.07)$ & $-.18^{*}(.10)$ & $.00(.818)$ & $.12 * *(.05)$ \\
Peer distance & $-.848(.89)$ & $-.95(.78)$ & $-1.03(1.08)$ & $-.77(1.03)$ \\
Peer communication frequency & $-3.43(2.14)$ & $-2.45(4.18)$ & $-3.33 *(1.73)$ & $-5.52 * * * *(1.46)$ \\
Control variables & & & & $13.31 * *(6.23)$ \\
$\quad$ Franchisee experience & $14.98 * *(4.26)$ & $14.73 * * *(3.47)$ & $-.91(.80)$ & $14.78 * * *(3.40)$ \\
$\quad$ Franchisee work floor hours & $-1.00(.84)$ & $-1.90(1.40)$ & .46 & $-.91 *(.70)$ \\
$\quad$ (Adjusted) $R^{2}$ & .57 & .44 & .51 \\
\hline
\end{tabular}

$n=33$

$* p<.10, * * p<.05, * * * p<.01, * * * * p<.001$, levels of significance

Finally, to assess the robustness of the empirical findings to alternative model specifications, we ran several alternative QR models: such as a model without peer sales quality, a model without peer operational quality, a model without both peer sales quality and peer operational quality and a model without peer distance (while always maintaining the controls). Either of these models yielded essentially the same results as those presented in Table 4. This suggests that the results can be considered robust.

\subsection{Results and discussion for structural network characteristics: network position}

H1a hypothesized that a franchisee's betweenness centrality in the peer network is positively associated with unit performance, and $\mathrm{H} 1 \mathrm{~b}$ proposed that the strength of this association is stronger for high performers than for medium and low performers. Supporting H1a, the OLS regression indeed shows a positive and statistically significant association: the more a franchisee is located on shortest paths between its peers, the higher its unit performance. Consistent with H1b, we find that the positive effect of centrality is stronger for high performers (a positive, statistically significant coefficient) than for low performers. In fact, the coefficient for low performers is not statistically significant, which indicates that low performers do not benefit from having a central position, whereas medium and high performers do. Because the difference between high and medium performers is not statistically significant $(F=1.13$, $p>.1)$, the hypothesis is largely supported.
These findings are in concert with the absorptive capacity argument (Tsai 2001; Van Wijk et al. 2008; Monteiro et al. 2008); as a result of their high absorptive capacity, high performers may benefit the most from having access to knowledge. The finding that low performers do not benefit at all also fits with this argument: their absorptive capacity is simply too low to recognize and be able to internalize the value of available knowledge in their peer network.

\subsection{Results and discussion for resource network characteristics: partner quality}

A franchisee's partner quality refers to peer sales quality ( $\mathrm{H} 2 \mathrm{a}$ and $\mathrm{b}$ ) and peer operational quality (H3a and b). We expected peer sales quality to be positively associated with unit performance ( $\mathrm{H} 2 \mathrm{a})$ and that this positive association is stronger for low performers than for medium and high performers (H2b). The OLS model does not uncover a statistically significant effect, so $\mathrm{H} 2 \mathrm{a}$ is not supported. However, the QR results do show differential effects of peer sales quality on unit performance. Since an OLS model generates a single coefficient for the (conditionally) 'average population', it misses the differentiating effect of peer sales quality on unit performance. Consistent with $\mathrm{H} 2 \mathrm{~b}$, we find that low performers benefit from a high peer sales quality (with $p<.088$, which is reasonable given the modest sample size), whereas the high and medium performers do not. In fact, high performers even suffer from a (small) negative association between partner sales quality and unit performance. Although the difference in 

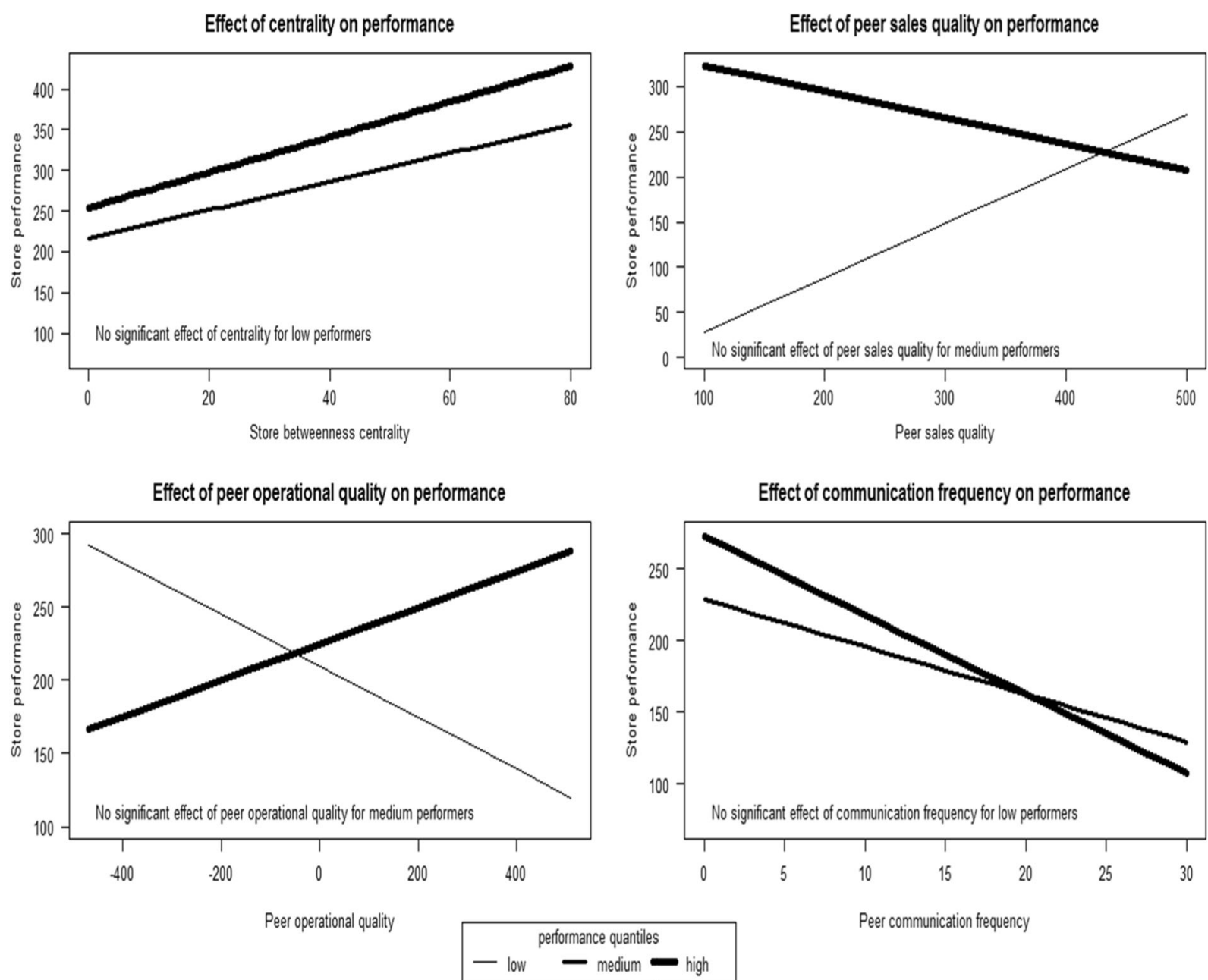

Fig. 2 Overview of networking effects for the three performance levels. Estimated effect of betweenness centrality, peer sales quality, peer operational quality and communication frequency on unit performance, each time with all other variables at their median

coefficients is small, the difference is statistically significant $(F=7.13, p<.01)$. Medium performers benefit nor suffer from having high or low average performing contacts. Apart from the coefficient for the high performers turning slightly negative, $\mathrm{H} 2 \mathrm{~b}$ is essentially supported. An explanation for this negative association can be found in the marginal benefits for the high performers relative to the costs (Watson 2007). The high performers in our data set already have a high level of performance and will thus learn less from other high sales performers, whereas they still suffer from the costs of networking. For the high performers, the costs of networking thus outweigh the benefits. value. Only those lines are shown that represent coefficients that are statistically significantly different from zero. The thickness of the line denotes the respective performance levels (running from thin to thick, see legend)

Regarding peer operational quality, we expected a positive association with unit performance (H3a) and that this positive association is stronger for high performers than for medium and for low performers (H3b). The OLS model again does not uncover an effect (thus rejecting $\mathrm{H} 3 \mathrm{a}$ ), whereas the QR model shows that effects actually differ along performance levels. Consistent with $\mathrm{H} 3 \mathrm{~b}$, the $\mathrm{QR}$ results show that high performers benefit positively and significantly from peer operational quality, whereas medium and low performers do not. The effect for low performers even turns negative (albeit only significant at $p<.09)$. This difference between the coefficients is statistically significant $(F=8.29, p<.01)$. Again, medium performers do not appear to benefit (or 
suffer) from having contacts with high financial performance. $\mathrm{H} 3 \mathrm{~b}$ is essentially supported; as expected, the high performers indeed benefit the most from the high operational quality partners; however, the slight negative association for the low performers was unexpected. An explanation for this latter result may be that the low performers suffer the costs from networking (Watson 2007), but on top of that, the knowledge from their network partners is too complex for them and does not fit their specific knowledge needs. Given these low performers' low absorptive capacity, this combination of costly and complex knowledge is likely to cause problems.

\subsection{Results and discussion for relational network characteristics: tie strength}

Hypotheses 4 and 5 relate to a franchisee's tie strength, consisting of peer distance and peer communication frequency. Regarding peer distance, we expected a negative association between peer distance and unit performance (H4a) with a stronger negative association for the low performers than for the medium and high performers (H4b). Both the OLS and QR models show no significant effects; hence, $\mathrm{H} 4 \mathrm{a}$ and $\mathrm{H} 4 \mathrm{~b}$ are not supported. Even though several networking studies have argued for and/or found partner distance as an important network characteristic affecting performance (e.g. Cramton 2001; Kolympiris and Kalaitzandonakes 2013; Dolfsma and Van der Eijk 2015), our study does not find statistically significant results. An explanation may be the relative homogeneity of units within franchise systems compared to other types of networks of entrepreneurs. Since franchisees all operate under the same business format in relatively similar local circumstances (especially in our study as explained in Section 3.1.1), the problems with knowledge transfer and interpretation as suggested by previous studies may be smaller. Moreover, developments in ICT in general (e.g. email and internet) and in franchise systems (e.g. benchmarking systems and intranet) may have facilitated knowledge transfer and the interpretation of knowledge from different local units (Brooks 2012).

Regarding peer communication frequency, we hypothesized that communication frequency is negatively associated with unit performance (H5a) and that this negative association is stronger for high performers than for medium and low performers (H5b). The OLS model does not uncover a significant effect (rejecting H5a), whereas the QR models show that the negative effect of interaction frequency is stronger for high and medium performers (negative, statistically significant coefficients) than for low performers (seen from the statistically insignificant coefficient). For medium and high performers, having increased frequency of promotionrelated contact with peers is negatively associated with their performance. The difference in effect between medium and high performers is not statistically significant $(F=1.27, p>.1)$, so they both appear to suffer negative consequences of similar strength. An explanation is that for medium and high performers the marginal benefits of having frequent contacts are outweighed by the costs of networking because the frequent contacts are likely to produce redundant knowledge (cf. Watson 2007; Stam et al. 2014). Hence, H5b is largely supported.

\section{Summary, conclusion and implications}

To summarize, our theoretical framework introduced three facets of franchisee networking (i.e. structural, resource and relational characteristics) that are hypothesized to affect franchisee unit performance. Additionally, the framework proposed that the strength of the effect of each facet of networking is likely to vary between franchisees with different levels of unit performance. Table 5 provides a summary of our key findings.

Based on our OLS and QR results, we can summarize our key findings as follows. Based on the results of the OLS analyses, the conclusion would be that only the structural characteristic betweenness centrality is positively related to franchisee unit sales performance (for the whole sample), and all other variables are not relevant. However, the QR results reveal a very different picture. Although the $\mathrm{QR}$ results confirm the rejection of hypotheses $4 \mathrm{a}$ and $4 \mathrm{~b}$ (peer distance shows no relationship with sales performance), all other hypotheses can be accepted for part of the performance distribution. Moreover, the differential effect of unit performance is consistently present as hypothesized in hypotheses $\mathrm{H} 1 \mathrm{~b}$, $\mathrm{H} 2 \mathrm{~b}, \mathrm{H} 3 \mathrm{~b}$ and H5b. High performers will benefit from a strong network position and peer operational quality, while they will suffer from having network relationships with peers with high sales quality and frequent communication. For the medium performers, only a strong network position will improve sales performance, and too much communication will come at the cost of 
Table 5 Summary of key findings

\begin{tabular}{|c|c|c|c|c|}
\hline Facet & Variable & Hypothesis & Result & Conclusion $^{\mathrm{a}}$ \\
\hline Structural & $\begin{array}{l}\text { Network } \\
\text { position }\end{array}$ & $\begin{array}{l}\text { H1a: positive effect of betweenness } \\
\text { centrality } \\
\text { H1b: stronger for high performers }\end{array}$ & $\begin{array}{l}\text { Supported } \\
\text { Largely } \\
\quad \text { supported }\end{array}$ & $\begin{array}{l}\text { Although betweenness centrality seems positive } \\
\text { for the sample as a whole, in fact it is only so for } \\
\text { the medium and high performers }\end{array}$ \\
\hline \multirow[t]{2}{*}{ Resource } & $\begin{array}{l}\text { Partner } \\
\text { quality }\end{array}$ & $\begin{array}{l}\text { H2a: positive effect of peer sales quality } \\
\mathrm{H} 2 \mathrm{~b} \text { : stronger for low performers }\end{array}$ & $\begin{array}{l}\text { Not } \\
\text { supported } \\
\text { Supported }\end{array}$ & $\begin{array}{l}\text { The expected positive effect of peer sales quality } \\
\text { exists for the low performers. The relation for } \\
\text { the other groups is less strong (for the high } \\
\text { performers, it is even negative) }\end{array}$ \\
\hline & & $\begin{array}{l}\text { H3a: positive effect of peer operational } \\
\text { quality } \\
\text { H3b: stronger for high performers }\end{array}$ & $\begin{array}{l}\text { Not } \\
\text { supported } \\
\text { Supported }\end{array}$ & $\begin{array}{l}\text { Peer operational quality has a positive effect for the } \\
\text { high performers: an effect that is stronger than } \\
\text { for the other groups. In fact, the relation for the } \\
\text { low performers is even negative }\end{array}$ \\
\hline \multirow[t]{2}{*}{ Relational } & Tie strength & $\begin{array}{l}\text { H4a: negative effect of peer distance } \\
\text { H4b: stronger for low performers }\end{array}$ & $\begin{array}{l}\text { Not } \\
\text { supported } \\
\text { Not } \\
\text { supported }\end{array}$ & $\begin{array}{l}\text { Peer distance has no significant effect on } \\
\text { franchisee unit sales performance }\end{array}$ \\
\hline & & $\begin{array}{l}\text { H5a: negative effect of peer } \\
\text { communication frequency } \\
\text { H5b: stronger for high performers }\end{array}$ & $\begin{array}{l}\text { Not } \\
\text { supported } \\
\text { Largely } \\
\text { supported }\end{array}$ & $\begin{array}{l}\text { Peer communication frequency has a negative } \\
\text { relationship with franchisee sales performance } \\
\text { for the medium and high performers (but not for } \\
\text { low performers) }\end{array}$ \\
\hline
\end{tabular}

${ }^{a}$ Conclusions on the 'a' hypotheses are based on OLS, and the conclusions on the ' $b$ ' hypotheses are based on QR

decreasing sales. Finally, for the low performers, having peer relationships with high sales performers will help to improve sales, while connecting with high operational performers will be counterproductive. Overall, we may conclude that what may be a blessing for one group of franchisee-entrepreneurs is actually a curse for some others.

As a general conclusion, our findings provide a deeper insight into the networking-performance link by developing a multi-faceted framework in a specific and clearly defined entrepreneurial context (i.e. a franchise system) and by taking into account an important contingency factor that may affect the networkingperformance relationship. Our results imply the relevance of the multi-faceted framework since the structural, relational and resource network facets of a franchisee's peer network all affect unit performance. Moreover, we find differential effects for franchiseeentrepreneurs at different ends of the performance distribution, which justifies the recent calls for more research on contingencies affecting the networkingperformance relationship (e.g. Stam et al. 2014; Rauch et al. 2016) and contingencies in a franchising context (e.g. Cochet et al. 2008; Kidwell et al. 2007). Finally, even though several networking studies have already pointed at the possible downsides of networking (e.g.
Watson 2007; Jack 2010; Rauch et al. 2016), our study is among the few to empirically demonstrate such negative effects of networking. Another important research implication is thus that future empirical research should take into account these 'dark sides' of networking.

Our study has managerial implications for both franchisors and franchisees. Our findings provide guidance for franchisors on how to orchestrate knowledge sharing among the franchisees in their franchise systems. Using information from their benchmarking systems, franchisors can target different franchisee performance groups with specific initiatives. Medium and high performing franchisees benefit from occupying central network positions but suffer from high communication frequency. Franchisors could build on these findings by organizing central events or virtual communities where these franchisees play an important role. Such initiatives help in supporting the central position of these franchisees, while preventing them from overextending their interpeer communication frequency. Centrally organized meetings and organized virtual meetings can also ensure that high performers continue being in touch with those franchisees with high operational quality.

For low performing franchisees, the franchisor could stimulate knowledge sharing with high sales quality peers. By carefully managing the formation of 
franchisee groups or committees, the franchisor could encourage low performers to be in touch with franchisees that have shown to be competent at consistently generating high levels of sales, stimulating knowledge flow to these low performers. The franchisor could also consider instruments to improve the low performers' absorptive capacity (e.g. via additional training) in order to increase these franchisees' network utilization. In addition to these franchisor initiatives, there is of course also a responsibility for franchisees to participate in their franchisor's initiatives to manage peer networking and to proactively manage their own networking behaviours and absorptive capacity.

\section{Limitations and suggestions for future research}

Studying a single franchise system allowed us to control for country, industry and franchise system differences and thus to improve internal validity at the expense of external validity (Davies et al. 2011). Given the limited availability of research on the association between franchisee networking characteristics and unit performance, the focus on internal validity was a deliberate choice (cf. Gibbert et al. 2008). Despite the modest sample size, we do find statistically significant associations between franchisee networking characteristics and franchisee unit performance, which is a clear indication of the presence of such associations. Although there are no reasons to expect radically different findings in other contexts, we recommend that the study is replicated in multiple countries, industries and franchise systems. As suggested by Stam et al. (2014) and Rauch et al. (2016), such future studies could then include system-level, industry-level or country-level contingencies that may affect the networking-performance relationship. Relatedly, our results have pointed at one franchisee-level contingency (i.e. franchisee unit performance) as an important factor in explaining the networkingfranchisee performance link. However, additional franchisee-level contingencies may explain if and to what extent franchisees benefit from peer networking, such as the franchisees' strategic orientations (e.g. Grünhagen and Mittelsteadt 2005; Darr and Kurtzberg 2000) or the franchisees' perceptions of intra-brand competition (e.g. Cochet et al. 2008). Moreover, just as our study did, such franchisee-level studies could also benefit from benchmarking data provided by the franchisor to facilitate comparison and to prevent common method bias.

Second, our focal franchise system has no companyowned units and only a few multi-unit franchisees. Even though this enabled us to study a group of franchisees with similar characteristics, an interesting area for future research would be to study differences in networking behaviours between franchisees and company managers and between single-unit and multi-unit franchisees. Several franchising researchers (e.g. Cliquet and Pénard 2012; Sorenson and Sørensen 2001) pointed out that franchisees may be more inclined than company managers to engage in local adaptation, which may imply that franchisees are more inclined than company managers to actively engage in knowledge sharing and networking behaviours. In a similar vein, multi-unit franchisees may behave differently from single-unit franchisees due to different strategic orientations and a larger scale of activities (Grünhagen and Mittelsteadt 2005; Dant et al. 2013). Multi-unit franchising is not as common in the Netherlands as in some other countries such as the USA; however, we recommend future studies to look for empirical settings to study this variable in more depth.

A further limitation of this paper is that we assume the relationship between networking behaviour and firm performance to be unidirectional and not reciprocal (which would account for the argument that performance may also affect an actor's networking characteristics). With this choice, we follow mainstream network research as presented in recent meta-analyses such as Rauch et al. (2016) and Stam et al. (2014); however, future research should take into account the possibility of reciprocal relationships.

Finally, from a methodological point of view, our study suggests that it may be valuable to use QR analyses in future research. In our analysis, only one out of five relevant coefficients was statistically significant in the OLS model and relying on OLS would result in researchers concluding that only a single effect is established in the data, whereas four of five variables do have statistically significant effects in the QR model. This is not the result of QR having higher power than OLS (that is generally not the case) but because QR is able to uncover effects that are not homogenous throughout the sample. By shifting attention from explaining the conditional mean to (multiple) conditional quantiles, researchers get findings at higher resolutions. We hope that this approach can inspire theorists and analysts alike. 


\section{Compliance with ethical standards}

Conflict of interest The authors declare that they have no conflict of interest.

\section{Appendix: a brief primer to Quantile Regression (QR)}

Regression is arguably the most common statistical method employed by researchers to study the relationships between variables - the purpose of regression analysis is to expose the relationship between a response variable and predictor variables. The most popular multivariable model for analysing a univariate continuous $Y$ is the linear model:

$y_{i}=\beta_{0}+\beta_{1} x_{i 1}+\ldots+\beta_{k} x_{i k}+\varepsilon_{i}$

where the $\varepsilon_{i}$ are identically, independently and normally distributed with mean 0 and a common, albeit unknown, variance $\sigma^{2}$; thus, $\varepsilon_{i} \sim N\left(0, \sigma^{2} I\right)$. Because of the assumption of a zero mean for the error term, the function $\beta_{0}+$ $\beta_{1} x_{i 1}+\ldots+\beta_{k} x_{i k}$ in (1) effectively models the mean value of $y$, given $x$-hence, the model's focus is on explaining the 'conditional mean': $E(Y \mid X)=X \beta$. The coefficients $\beta$ are typically estimated using an ordinary least squares procedure where $\beta$ is determined such that it minimizes $\sum\left(Y_{i}-X \beta\right)^{2}$. OLS regression provides two pieces of information: (1) the intercept coefficient, which is an estimate of $Y$ when $X$ is zero, and (2) the slope coefficient, which represents the incremental change in $Y$ for a one-unit change in $X$. If, for example, a fitted regression model with two predictors were to yield $Y=1+2 X_{1}+3 X_{2}$, this would mean that the average $Y$ increases by 2 when $X_{1}$ increases by 1 . That same average $Y$ increases by 3 when $X_{2}$ increases by 1 .

$\mathrm{QR}$ is an approach to modelling $Y$ that allows a researcher to shift focus from the conditional mean to other parts of the conditional distribution of $Y$. QR models conditional quantiles of interest (rather than the conditional mean) and allows the researcher to investigate the effects of the predictors for different quantiles. Quantile regression was developed by Koenker and Bassett (1978) as an extension of (1) and is written as:

$y_{i}=\beta_{0}^{q}+\beta_{1}^{q} x_{i 1}+\ldots+\beta_{k}^{q} x_{i k}+\varepsilon_{i}^{q}$

where $0<q<1$ represents the proportion of the population having scores below the quantile at $q$. For example, for $q=.50$, we model the 50th percentile of the distribution of $Y$ (i.e. the median $Y$, this is better known as 'median regression'), conditional on the values of $X$ : $Q_{q}(Y \mid X)=X \beta_{q}$. Coefficients can be estimated by an optimization function that minimizes a sum of weighted absolute vertical deviations, where the weight is $1-q$ for points below the fitted line and $q$ for points above the fitted line (Davino et al. 2014). QR regression provides two pieces of information at each estimated quantile: (1) the intercept coefficient, which is an estimate of $Y$ at that quantile of $Y$, and (2) the slope coefficient, which represents the incremental change in $Y$ for a one-unit change of $X$ at that quantile of $Y$. If, for example, a fitted regression model with two predictors were to yield $Y$ $=1+2 X_{1}+3 X_{2}$ (for $q=.70$ ), this means that the $Y$ at the 70th quantile increases by 2 when $X_{1}$ increases by 1 . That same $Y$ at the 70th quantile increases by 3 when $X_{2}$ increases by 1 . For $Y$ at another quantile, the relation between $Y$ and $X$ might be different which would yield different intercept and regression coefficients.

The conditional mean approach has attractive properties, such as statistical efficiency and ease of calculation and interpretation. However, the approach also has important drawbacks. To compute $p$ values and confidence limits in (1), we have to assume error term normality with constant variance. Violation of the normality assumption or the assumption of constant variance can cause inaccuracy of standard errors. The normality assumption typically requires a large sample size, in order for the researcher to be somewhat at ease with the normality assumption. Alternatively, the QR approach makes no distributional assumptions other than continuity of $Y$ and, hence, does not rely on large samples to make distributional assumptions realistic. Second, heavy-tailed distributions commonly occur in social phenomena, leading to a preponderance of outliers. The conditional mean model is heavily influenced by outliers (Hao and Naiman 2007). The QR model is not sensitive to outliers. Related to this, researchers often transform their dependent variable in order to make it more symmetric and well-behaved. For example, sales or income data are often log-transformed before running a regression model. However, the model in (1) is not invariant to such transformations. Alternatively, the QR model is invariant to (monotonic) transformations (such as the logarithm). In fact, the QR model is not affected by skewness of the dependent variable - it is entirely robust against it - and nothing is gained (or lost) by transforming $Y$ beforehand. This is why we used sales 
as a dependent variable in our model, without needing to $\log$-transform it first.

The most important difference between the models is that the model in (1) essentially assumes that it is appropriate for all data, which has been termed the 'onemodel assumption', whereas QR shifts the focus from the conditional mean to other parts of the distribution of $Y$. For instance, studies of economic inequality are often interested in the poor (lower tail) and the rich (upper tail), rather than (only) in the mean earners (Hao and Naiman 2007). The conditional mean model cannot deal with this situation gracefully, but the QR model is explicitly suited for this kind of inquiry. In OLS, estimating potentially different effects for different quantiles would require to divide the sample into subsamples; for the research question in our paper, a researcher would have to split the data into three groups: low performers, median performers and high performers. This has severe drawbacks: it reduces the sample size for each group to one-third of the overall sample and drastically reduces the variance in the dependent variable (as the value of the dependent variable is the criterion by which the subgroups were created). Alternatively, QR does not require breaking up the data into subsamples: the complete data are employed to estimate the coefficients at each of the quantiles of interest (the local behaviour near the specific quantile weighs more than the remote behaviour of the distribution).

When multiple quantiles are of interest (as will frequently be the case when QR is applied), a researcher will often want to test whether found interquantile differences are statistically significant (where the same set of X's is included for each quantile). This can easily be tested by considering the covariances of cross-quantile estimates and computing the $p$ values of the resulting $F$ statistic for the encompassing Wald tests (Koenker and Bassett 1982). This approach allows one to test whether $\beta_{i}^{q}$ for two or more different $q$ 's are statistically different from one another (Davino et al. 2014). Researchers do not have to calculate these statistics themselves; software that implements QR will do this for them. When the regression coefficient for a specific quantile is not statistically significant different from zero, a test of the significance of the interquantile differences between it and another quantile is not relevant.

An increasing number of software packages for quantile regression allows researchers to apply $\mathrm{QR}$ to their data, although OLS-type models such as (1) have been implemented in statistical software more widely and are routinely available in more software packages than QR.

Open Access This article is distributed under the terms of the Creative Commons Attribution 4.0 International License (http:// creativecommons.org/licenses/by/4.0/), which permits unrestricted use, distribution, and reproduction in any medium, provided you give appropriate credit to the original author(s) and the source, provide a link to the Creative Commons license, and indicate if changes were made.

\section{References}

Adler, P. S., \& Kwon, S. W. (2002). Social capital: prospects for a new concept. Academy of Management Review, 27(1), 1740. doi:10.5465/AMR.2002.5922314.

Afuah, A. (2013). Are network effects really all about size? The role of structure and conduct. Strategic Management Journal, 34(3), 257-273. doi:10.1002/smj.2013.

Aldrich, H. E., \& Zimmer, C. (1986). Entrepreneurship through social networks. In D. L. Sexton \& W. Smilor (Eds.), The art and science of entrepreneurship (pp. 2-23). Cambridge: Ballinger.

Arenius, P., \& De Clercq, D. (2005). A network-based approach on opportunity recognition. Small Business Economics, 24(3), 249-265. doi:10.1007/s11187-005-1988-6.

Arnett, D. B., \& Wittmann, C. M. (2014). Improving marketing success; the role of tacit knowledge exchange between sales and marketing. Journal of Business Research, 67(3), 324 331. doi:10.1016/j.busres.2013.01.018.

Baker, W. E., Grinstein, A., \& Harmancioglu, N. (2016). Whose innovation performance benefits more from external networks: entrepreneurial or conservative firms? Journal of Product Innovation Management, 33(1), 104-120. doi:10.1111/jpim.12263.

Batjargal, B. (2003). Social capital and entrepreneurial performance in Russia: a longitudinal study. Organization Studies, 24(4), 535-556. doi:10.1177/0170840603024004002.

Brandes, U. (2001). A faster algorithm for betweenness centrality. Journal of Mathematical Sociology, 25(2), 163-177. doi:10.1080/0022250X.2001.9990249.

Brooks, C. (2012). The effect of information and communications technology (ICT) on franchisee to franchisor relationships. Doctorate Thesis. Bournemouth University.

Chiu, C. M., Hsu, M. H., \& Wang, E. T. G. (2006). Understanding knowledge sharing in virtual communities: an integration of social capital and social cognitive theories. Decision Support Systems, 42(3), 1872-1888. doi:10.1016/j.dss.2006.04.001.

Christen, M., Boulding, W., \& Staelin, R. (2009). Optimal market intelligence strategy when management attention is scarce. Management Science, 55(4), 526-538. doi:10.1287 /mnsc. 1080.0988.

Cliquet, G., \& Pénard, T. (2012). Plural form franchise networks; a test of Bradach's model. Journal of Retailing and Consumer Services, 19(1), 159-167. doi:10.1016/j.jretconser.2011.11.005.

Cochet, O., Dormann, J., \& Ehrmann, T. (2008). Capitalizing on franchisee autonomy: relational forms of governance as 
controls in idiosyncratic franchise dyads. Journal of Small Business Management, 46(1), 50-72. doi:10.1111/j.1540627X.2007.00231.x.

Cohen, W., \& Levinthal, D. (1990). Absorptive capacity; a new perspective on learning and innovation. Administrative Science Quarterly, 35, 128-152. doi:10.2307/2393553.

Combs, J. G., Ketchen, D. J., \& Short, J. C. (2011). Franchising research: major milestones, new directions, and its future within entrepreneurship. Entrepreneurship: Theory \& Practice, 35(3), 413-425. doi:10.1111/j.15406520.2011.00443.x.

Cooper, A., Ramachandran, M., \& Schoorman, D. (1997). Time allocation patterns of craftsmen and administrative entrepreneurs: implications for financial performance. Entrepreneurship, Theory \& Practice winter, 22(2), 123136.

Cramton, C. D. (2001). The mutual knowledge problem and its consequences for dispersed collaboration. Organization Science, 12(3), 346-371. doi:10.1287/orsc.12.3.346.10098.

Croonen, E. P. M., Brand, M. J., \& Huizingh, K. R. E. (2016). To be entrepreneurial or not to be entrepreneurial? Explaining differences in franchisee entrepreneurial behaviour within a franchise system. International Entrepreneurship and Management Journal, 12(2), 531-553. doi:10.1007/s11365014-0352-1.

Dada, O., Watson, A., \& Kirby, D. (2012). Toward a model of franchisee entrepreneurship. International Small Business Journal, 30(5), 559-583. doi:10.1177/0266242610376078.

Dant, R. P., \& Gundlach, G. T. (1999). The challenge of autonomy and dependence in franchised channels of distribution. Journal of Business Venturing, 14(1), 35-67. doi:10.1016 /S0883-9026(97)00096-7.

Dant, R. P., Grünhagen, M., \& Windsperger, J. (2011). Franchising research frontiers for the twenty-first century. Journal of Retailing, 87(3), 253-268. doi:10.1016/j.jretai.2011.08.002.

Dant, R. P., Weaven, S., Baker, B., \& Jeon, H. (2013). An introspective examination of single-unit versus multi-unit franchisees. Journal of the Academy of Marketing Science, 41(4), 473-496. doi:10.1007/s11747-011-0265-2.

Darr, E. D., \& Kurtzberg, T. R. (2000). An investigation of partner similarity dimensions on knowledge transfer. Organizational Behavior and Human Decision Processes, 82(1), 28-44. doi:10.1006/obhd.2000.2885.

Darr, E. D., Argote, L., \& Epple, D. (1995). The acquisition, transfer, and depreciation of knowledge in service organizations: productivity in franchises. Management Science, 41(11), 1750-1762. doi:10.1287/mnsc.41.11.1750.

Davies, M. A. P., Lassar, W., Manolis, C., Prince, M., \& Winsor, R. D. (2011). A model of trust and compliance in franchise relationships. Journal of Business Venturing, 26(3), 321-340. doi:10.1016/j.jbusvent.2009.09.005.

Davino, C., Furno, M., \& Vistocco, D. (2014). Quantile regression: theory and applications. Chichester: Wiley.

Dolfsma, W., \& Van der Eijk, R. (2015). Distances in organizations: innovation in an R\&D lab. British Journal of Management, 00, 1-16. doi:10.1111/1467-8551.12114.

Emans, B. (2004). Interviewing, theory, techniques and training. Groningen: Stenfert Kroese.

Fang, E., Lee, J., Palmatier, R., \& Han, S. (2016). If it takes a village to foster innovation, success depends on the neighbors: the effects of global and ego networks on new product launches. Journal of Marketing Research, 53(3), 319-337. doi:10.1509/jmr.13.0226.

Fenwick, G. D., \& Strombom, M. (1998). The determinants of franchisee performance: an empirical investigation. International Small Business Journal, 16(4), 28-46. doi:10.1177/0266242698164002.

Freeman, L. C. (1977). A set of measures of centrality based on betweenness. Sociometry, 40(1), 35-41. doi:10.2307 /3033543.

Freeman, L. C. (1979). Centrality in social networks conceptual clarification. Social Networks, 1(3), 215-239. doi:10.1016 /0378-8733(78)90021-7.

Gassenheimer, J. B., Baucus, D. B., \& Baucus, M. S. (1996). Cooperative arrangements among entrepreneurs: an analysis of opportunism and communication in franchise structures. Journal of Business Research, 36(1), 67-79. doi:10.1016 /0148-2963(95)00164-6.

Gibbert, M., Ruigrok, W., \& Wicki, B. (2008). What passes as a rigorous case study? Strategic Management Journal, 29(13), 1465-1474. doi:10.1002/smj.722.

Goedhuys, M., \& Sleuwaegen, L. (2010). High-growth entrepreneurial firms in Africa; a quantile regression approach. Small Business Economics, 34, 31-51. doi:10.1007/s11187-0099193-7.

Gorovaia, N., \& Windsperger, J. (2013). Determinants of knowledge transfer strategy in franchising: integrating knowledgebased and relational governance perspectives. The Service Industries Journal, 33(12), 1117-1134. doi:10.1080 /02642069.2011.632003.

Grünhagen, M., \& Mittelsteadt, R. A. (2005). Entrepreneurs or investors: do multi-unit franchisees have different philosophical orientations? Journal of Small Business Management, 43(3), 207-225. doi:10.1111/j.1540-627X.2005.00134.x.

Hanneman, R. A., \& Riddle, M. (2005). Introduction to social network methods. Riverside: University of California, Riverside published in digital form at http://faculty.ucr. edu/ hanneman/.

Hansen, M. (2002). Knowledge networks: explaining effective knowledge sharing in multiunit companies. Organization Science, 13(3), 231-248. doi:10.1287/orsc.13.3.232.2771.

Hao, L., \& Naiman, D. Q. (2007). Quantile regression. Thousand Oaks: Sage.

Hayter, C. S. (2015). Conceptualizing knowledge-based entrepreneurship networks: perspectives from the literature. Small Business Economics, 41, 899-911. doi:10.1007/s11187013-9512-x.

Hoang, H., \& Antoncic, B. (2003). Network-based research in entrepreneurship: a critical review. Journal of Business Venturing, 18(2), 165-187. doi:10.1016/S0883-9026(02)00081-2.

Jack, S. L. (2010). Approaches to studying networks: implications and outcomes. Journal of Business Venturing, 25(1), 120 137. doi:10.1016/S0883-9026(02)00081-2.

Jensen, R. J., \& Szulanski, G. (2007). Template use and the effectiveness of knowledge transfer. Management Science, 53(11), 1716-1730. doi:10.1287/mnsc.1070.0740.

Kalnins, A., \& Mayer, K. J. (2004). Franchising, ownership, and experience: a study of pizza restaurant survival. Management Science, 50(12), 1716-1728. doi:10.1287/mnsc.1040.0220.

Kaufmann, P. J., \& Eroglu, S. (1998). Standardization and adaptation in business format franchising. Journal of Business Venturing, 14(1), 69-85. doi:10.1016/S0883-9026(97)00097-9. 
Ketchen, D. J., Short, J. C., \& Combs, J. G. (2011). Is franchising entrepreneurship? Yes, no and maybe so. Entrepreneurship: Theory \& Practice, 35(3), 583-593. doi:10.1111/j.15406520.2011.00442.x.

Kidwell, R. E., Nygaard, A., \& Silkoset, R. (2007). Antecedents and effects of free riding in the franchisor-franchisee relationship. Journal of Business Venturing, 22(4), 522-544. doi:10.1016/j.jbusvent.2006.06.002.

Kim, P. H., \& Aldrich, H. E. (2005). Social capital and entrepreneurship. Foundations and Trends in Entrepreneurship, 1(2), $1-52$.

Knott, A. M. (2003). The organizational routines factor market paradox. Strategic Management Journal, 24(10), 929-943. doi:10.1002/smj.315.

Koenker, R. (2005). Quantile regression. New York: Cambridge University Press.

Koenker, R., \& Bassett, G. (1978). Regression quantiles. Econometrica, 46(1), 33-50. doi:10.2307/1913643.

Koenker, R. W., \& Bassett, G. W. (1982). Robust tests for heteroscedasticity based on regression quantiles. Econometrica, 50, 43-61. doi:10.2307/1912528.

Kolympiris, C., \& Kalaitzandonakes, N. (2013). Geographic scope of proximity effects among small life sciences firms. Small Business Economics, 40, 1059-1086. doi:10.1007/s11187012-9441-0.

Kwon, S. W., \& Adler, P. S. (2014). Social capital: maturation of a field of research. Academy of Management Review, 38(4), 412-422. doi:10.5465/amr.2014.0210.

Lai, H. C. (2016). When is betweenness centrality useful to firms pursuing technological diversity? An internal-resources view. Technology Analysis \& Strategic Management, 28(5), 507523. doi:10.1080/09537325.2015.1105949.

Lane, P. J., \& Lubatkin, M. (1998). Relative absorptive capacity and interorganizational learning. Strategic Management Journal, 19(5), 461-477. doi:10.1002/(SICI)1097-0266 (199805)19:5<461::AID-SMJ953>3.0.CO;2-L.

Michael, S. C., \& Combs, J. G. (2008). Entrepreneurial failure; the case of franchisees. Journal of Small Business Management, 46(1), 73-90. doi:10.1111/j.1540-627X.2007.00232.x.

Monteiro, L. F., Arvidson, N., \& Birkinshaw, J. (2008). Knowledge flows within multinational corporations: explaining subsidiary isolation and its performance implications. Organization Science, 19(1), 90-107. doi:10.1287 /orsc. 1070.0264.

Moran, P. (2005). Structural vs. relational embeddedness: social capital and managerial performance. Strategic Management Journal, 26(12), 1129-1151. doi:10.1002/smj.486.

Mumdžiev, N., \& Windsperger, J. (2011). The structure of decision rights in franchising networks: a property rights perspective. Entrepreneurship Theory and Practice, 35(3), 449-465. doi:10.1111/j.1540-6520.2011.00440.x.

Noble, C. H., Sinha, R. K., \& Kumar, A. (2002). Market orientation and alternative strategic orientations: a longitudinal assessment of performance implications. Journal of Marketing, 66(4), 25-39. doi:10.1509/jmkg.66.4.25.18513.

Noble, S. M., Griffith, D. A., \& Adjei, M. T. (2006), Drivers of local merchant loyalty; understanding the influence of gender and shopping motives. Journal of Retailing, 82(3), 177-188.

Rabobank (2014). Rabobank Cijfers en Trends, Rabobank, April 30, 2014.
Ramdani, D., \& Van Witteloostuijn, A. (2010). The impact of board dependence and CEO duality on firm performance: a quantile regression analysis for Indonesia, Malaysia, South Korea and Thailand. British Journal of Management, 21, 607-626. doi:10.1111/j.1467-8551.2010.00708.x.

Rauch, A., Rosenbusch, N., Unger, J., \& Frese, M. (2016). The effectiveness of cohesive and diversified networks: a metaanalysis. Journal of Business Research, 69(2), 554-568. doi:10.1016/j.jbusres.2015.05.011.

Reinholt, M., Pedersen, T., \& Foss, N. J. (2011). Why a central network position isn't enough: the role of motivation and ability for knowledge sharing in employee networks. Academy of Management Journal, 54(6), 1277-1297.

Ritter, T., \& Gemünden, H. G. (2003). Network competence; its impact on innovation success and its antecedents. Journal of Business Research, 56, 745-755. doi:10.1016/S0148-2963 (01)00259-4.

Rodan, S., \& Galunic, C. (2004). More than network structure: how knowledge heterogeneity influences managerial performance and innovativeness. Strategic Management Journal, 25(6), 541-562. doi:10.1002/smj.398.

Seo, J. H., Perry, V. G., Tomczyk, D., \& Solomon, G. T. (2014). Who benefits most? The effects of managerial assistance on high- versus low-performing small businesses. Journal of Business Research, 67, 2845-2852. doi:10.1016/j. jbusres.2012.07.003.

Slotte-Kock, S., \& Coviello, N. (2009). Entrepreneurship research on network processes: a review and ways forward. Entrepreneurship Theory \& Practice, 34(1), 1-27. doi:10.1111/j.1540-6520.2009.00311.x.

Soh, P. (2010). Network patterns and competitive advantage before the emergence of a dominant design. Strategic Management Journal, 31, 438-461. doi:10.1002/smj.819.

Sorenson, O., \& Sørensen, J. B. (2001). Research note: finding the right mix: franchising, organizational learning, and chain performance. Strategic Management Journal, 22(6/7), 713724. doi:10.1002/smj.185.

Stam, W., Arzlanian, S., \& Elfring, T. (2014). Social capital of entrepreneurs and small firm performance: a meta-analysis of contextual and methodological moderators. Journal of Business Venturing, 29(1), 152-173. doi:10.1016/j. jbusvent.2013.01.002.

Stuart, T. E. (2000). Interorganizational alliances and the performance of firms; a study of growth and innovation rates in a high-technology industry. Strategic Management Journal, 21, 791-811. doi:10.1002/1097-0266(200008)21:8<791 :AID-SMJ121>3.0.CO;2-K.

Szulanski, G., \& Jensen, R. J. (2006). Presumptive adaptation and the effectiveness of knowledge transfer. Strategic Management Journal, 27, 937-957. doi:10.1002/smj.551.

Szulanski, G., \& Jensen, R. J. (2008). Growing through copying; the negative consequences of innovation on franchise network growth. Research Policy, 37(10), 1732-1741. doi:10.1016/j.respol.2008.08.012.

Tran, Y., Mahnke, V., \& Ambos, B. (2010). The Effect of Quality and Timing of Headquarters-initiated Knowledge Flows on Subsidiary Performance. Management International Review, 50, 493-511. doi:10.1007/s11575-010-0046-z.

Tsai, W. (2001). Knowledge transfer in intraorganizational networks; effects of network position and absorptive capacity on business unit innovation and performance. Academy of 
Management Journal, 44(5), 996-1004. doi:10.2307 13069443.

Turner, T., \& Pennington III, W. (2015). Organizational networks and the process of corporate entrepreneurship: how the motivation, opportunity, and ability to act affect firm knowledge, learning and innovation. Small Business Economics, 45, 447-463. doi:10.1007/s11187-015-9638-0.

Uzzi, B. (1997). Social structure and competition in interfirm networks: the paradox of embeddedness. Administrative Science Quarterly, 42(1), 35-67. doi:10.2307/2393808.

Wasserman, S., \& Faust, K. (1994). Social network analysis: methods and applications. New York: Cambridge University Press.

Watson, J. (2007). Modeling the relationship between networking and firm performance. Journal of Business Venturing, 22, 852-874. doi:10.1016/j.jbusvent.2006.08.001.

Wijk van, R., Jansen, J. P. J., \& Lyles, M. A. (2008). Inter- and intra-organizational knowledge transfer: a meta-analytic review and assessments of its antecedents and consequences.
Journal of Management Studies, 45(4), 830-853. doi:10.1111/j.1467-6486.2008.00771.x.

Windsperger, J. (2004). Centralization of franchising networks: evidence from the Austrian franchise sector. Journal of Business Research, 57(12), 1361-1369. doi:10.1016 /S0148-2963(03)00068-7.

Winter, S. G., \& Szulanski, G. (2001). Replication as strategy. Organization Science, 12(6), 730-743. doi:10.1287 /orsc.12.6.730.10084.

Winter, S. G., Szulanski, G., Ringov, D., \& Jensen, R. J. (2012). Reproducing knowledge: inaccurate replication and failure in franchise organizations. Organization Science, 23(3), 672685. doi: $10.1287 /$ orsc. 1110.0663.

$\mathrm{Xu}, \mathrm{S}$. (2015). Balancing the two knowledge dimensions in innovation efforts: an empirical examination among pharmaceutical firms. Journal of Product Innovation Management, 32(4), 610-621. doi:10.1111/jpim.12234.

Zaheer, A., \& Bell, G. G. (2005). Benefiting from network position: firm capabilities, structural holes, and performance. Strategic Management Journal, 26, 809-825. doi:10.1002/smj.482. 